\title{
The Effect of Interlingual and Intralingual, Verbatim and Nonverbatim Subtitles on L2 Vocabulary Comprehension and Production
}

\author{
Abbas Ali Zarei \\ Imam Khomeini International University, Qazvin, Iran \\ Email: aazarei@ikiu.ac.ir \\ Zohreh Rashvand \\ Izlamic Azad University, Takestan, Iran
}

\begin{abstract}
The present study sought to investigate the effect of verbatim and nonverbatim interlingual and intralingual subtitles on $L_{2}$ vocabulary comprehension and production. To this end, four groups of 30 language learners studying conversational English in two language institutes in Qazvin participated in the study. Each of the groups watched the same movie with a different type of subtitling: a) verbatim interlingual, b) nonverbatim interlingual, c) verbatim intralingual and d) nonverbatim intralingual subtitles. The participants also received a vocabulary pretest and vocabulary comprehension and production post-tests. Two separate Two-Way ANOVA procedures were used to analyze the obtained data. The results revealed that nonverbatim subtitles resulted in more vocabulary comprehension regardless of whether they were interlingual or intralingual, whereas intralingual subtitles were more conductive to vocabulary production irrespective of whether they were verbatim or nonverbatim.
\end{abstract}

Index Terms-interlingual subtitles, intralingual subtitles, verbatim subtitles, nonverbatim subtitles, vocabulary comprehension, vocabulary production

\section{INTRODUCTION}

People do not watch television programs and videos only to have fun. Television programs and videos can be quite instructive. Foreign language learning is one of the many diverse areas that can benefit from such media. Today, a foreign language can also be learnt through watching subtitled programs in and out of the class. Subtitles can be divided into several kinds. In this study we will discuss intralingual versus interlingual and verbatim versus nonverbatim subtitles.

The language of intralingual subtitles is the same as that of the dialogues of the film while subtitles and dialogues have two different languages in interlingual subtitles. Verbatim subtitling refers to everything spoken including pause fillers, hesitations, etc. on the screen, whereas nonverbatim subtitling refers to summarized subtitles conveying only necessary information to get the film. The relevant literature is witness to considerable controversy as to the effect of the various kinds of subtitled films and videos on vocabulary learning. So, the purpose of this study is to focus primarily on the nature of subtitles and their effects on vocabulary comprehension and production. It aims to find answers to the following research questions:

1. Is there a significant difference between the effects of interlingual and intralingual verbatim and nonverbatim subtitling on $\mathrm{L}_{2}$ vocabulary comprehension?

2. Is there a significant difference between the effects of interlingual and intralingual verbatim and nonverbatim subtitling on $\mathrm{L}_{2}$ vocabulary production?

\section{REVIEW OF THE RELATED LITERATURE}

According to Reich (2006), subtitling is a branch of translation called audiovisual translation in which viewers can read statements of dialogues on the screen as well as watch the images and listen to the dialogues. Neves (2008) is of the opinion that captioning and subtitling have exactly the same definitions although some make a distinction and believe that captioning is considered to be for both deaf and hearing-impaired viewers while subtitling is special to hearers.

According to Gerzymisch-arbogast (2008), subtitles are the written translation of film dialogues appearing synchronously with the corresponding dialogues produced on the screen. He adds that the process of subtitling involves 3 steps: 1) from one 'language' to another 2) from verbal speech to a written text 3) from a non-condensed (verbatim) to a condensed (nonverbatim) form of text. 
Concerning the history of subtitles, Cintas (2005) avows that subtitled films were marketed in the second half of 1970s. Reich (2006) holds that although there were voiceless films in cinemas at the beginning of the film-making history, the producers tried to find a solution to convey the dialogues to the viewers. They finally decided to write short statements on a paper and insert them between the film sequences. The written statements were called intertitles. Subtitles are new forms of intertitles.

Eken (2003) suggests that foreign language teachers exploit the media including television, video, and internet as a motivational tool in and out of class. Similarly, Koolstra and Beentjes (1999) believe that watching television programs is a useful way to learn a foreign language. They also maintain that many Dutch students learn English from television and radio more than in schools. Wang and Shen (2007) believe that if something is to be learnt, it must be noticed. Watching television programs makes this possible. It is, however, difficult for learners to understand films if they rely only on listening comprehension. Here subtitling plays a prominent role.

Meskill (1996) believes that subtitled video, a combination of pictures, sounds, and texts, do not hinder comprehension, but rather enhance it. Furthermore, Chang (2004) demonstrates that foreign films, especially when subtitled, increase viewers' motivation to acquire that language. Similarly, Danan (2004) maintains that media have a motivational effect on language learning. In this respect, video alone is not enough. He suggests that stakeholders exploit subtitling although there is some belief that these technologies are distracting and result in listening laziness.

Opposed to the idea of listening laziness through watching subtitled videos, Zanon (2006) concludes that using subtitled video in language classes causes students to be more relaxed while watching. In addition, because it is a nice and pleasurable activity, it improves language comprehension and acquisition. Watching subtitled videos motivates students and familiarizes them with the target culture. It also has an effective role in acquiring correct pronunciation and developing new words and idioms. In the same vein, Bravo (2005) maintains that watching subtitled movies enhances the learners' motivation and results in incidental acquisition of foreign languages.

According to Schroter (2005), subtitling is a form of translation called "additive translation" (p. 28). Because paralinguistic features including intonation and stress patterns, gestures, and facial expressions affect meaning, both verbal and nonverbal utterances are supposed to be conveyed into subtitles. Although some believe that subtitling is advantageous over dubbing due to presenting original dialogues, Schroter argues that both have the same effect on the audience's understanding. He also believes that although it is a fact that subtitles distract viewers to focus on image, it is not really too difficult to read, watch, and listen to all at once.

\section{A. Addressees of Subtitling}

Neves (2008) states that the addressees of subtitles do not belong to one unique group; therefore, subtitlers have to consider various age groups and social backgrounds.

According to Chang (2004), even though subtitling was originally formulated for deaf and hard of hearing, it is also beneficial for second language learners. Similarly, Zanon (2006) and Caimi (2006) maintain that due to creating a combination of sound, image, and text, this approach can be used for all types of students.

\section{Benefits and pitfalls of subtitling}

Koolstra and Beentjes (1999) believe that interlingual subtitles contribute to learning expressions, pronunciation, syntax, and connotations as well as vocabulary. They found that interlingual subtitling has three main advantages over dubbing: the first is that subtitling is cheaper than dubbing. The second is related to the actors' original voices, which certainly affect comprehension. The last, and the most important, is that it may result in incidental language learning. They also state that there are a number of concerns about subtitling. That is, in addition to distracting viewers, it may create problems for poor readers and children because it is usually quick. In addition, Cintas (2005) maintains that although subtitling is a good language teaching instrument, many stakeholders cannot exploit it because of the high price.

According to Zanon (2006), subtitling enjoys many advantages; it motivates learners and makes them secure and self-confident. Besides, it can help language learners to monitor their speech and find new vocabulary. He also maintains that in spite of all advantages, the drawbacks of subtitling should not be overlooked. For instance, reading of subtitles may gradually become a habit and create a false confidence.

\section{Interlingual and intralingual subtitling}

Neves (2008) makes a distinction between interlingual and intralingual subtitles. The language of intralingual subtitles is the same as that of dialogues, whereas the language of interlingual subtitles is different from that of the audio.

Bravo (2005) believes that both interlingual and intralingual subtitles result in language learning. He comments that learners of lower levels of proficiency are supposed to work with the first, whereas advanced learners benefit from the second to develop pronunciation and their knowledge of words and idioms.

Regarding intralingual subtitling, Caimi (2006) comments that it affects students' memories, develops their listening and reading comprehension, enhances their self-confidence, and replaces learning with entertainment. He maintains that there are two types of intralingual subtitles: the first is special to deaf or hearing-impaired viewers in which dialogues as well as every other sound are subtitled on the screen. In fact, this kind of subtitling is viewed as an "accessibility aid" (p. 85). The second kind has been formulated for people whose language is different from that being spoken in the film. In 
this kind, subtitling is regarded as a "didactic aid" (p. 85). Caimi believes that intralingual subtitling for didactic aid improves second language learners' listening comprehension due to the reproduction of oral language in written form.

According to Danan (2004), intralingual subtitles are called "captions" and interlingual ones are referred to as "standard subtitles" (pp. 67, 68). He believes that although both increase the learners' motivation, captioning suffers a number of limitations, whereas standard subtitling leads to incidental language learning. For example, he argues that captioning is suitable for beginners only if adapted to a primary level of linguistic ability.

Stewart and Pertusa (2004) hypothesize that films subtitled in the target language are more appropriate foreign language learning tools for English learners although most English instructors use English subtitled films in foreign language classes. They avow that one of the biggest drawbacks for English subtitling is the neglect of the listening skill. On the other hand, Bird and Williams (2002) and Schmidt (2007) maintain that one of the best ways of language learning is watching intralingually subtitled programs. They state that because word boundaries are clear and there are no accent variations, language learners comprehend and learn language to a greater extent.

\section{Verbatim versus nonverbatim subtitles}

In verbatim subtitles, oral materials (exactly what is said) are written at the bottom of the screen. So, it is the best opportunity for language learners to be familiar with spoken language aurally and visually (Meskill, 1996). Yet, Neves (2008) states that deaf and hard of hearing viewers as well as foreign language learners prefer verbatim subtitles because they want an equal stand with hearers; however, he believes that it is a big mistake because they have different needs and expectations. For instance, since they read subtitles slower than hearers and native viewers, they lose time while reading extra information in verbatim subtitles. In much the same vein, Caimi (2006) argues that factors such as duration of subtitles, the screen space, the speed of the dialogues, and the viewers' reading speed all influence comprehension and suggests that subtitlers use simplification and omission to eliminate redundancies in order to transfer more easily the film message. Gerzymisch-arbogast (2008) argues that one third of utterances need to be reduced if subtitles are to be readable. To this end, subtitlers should make use of summarizing, paraphrasing, and integrating processes.

Similarly, Cordella (2007) advocates the use of nonverbatim subtitles. In his study, Cordella found that omitting some aural informal features and reducing language particles such as articles and prepositions leads to clearer texts and, consequently, the audience's better understanding. Moreover, adding some linguistic features as well as making subtitles longer was also found to be helpful to film comprehension. Lever (1998) and Schroter (2005) report similar findings.

On the other hand, Schilperoord, Groot, and Son (2005) are among the proponents of verbatim subtitling who avow that "relational coherence" (p. 404) impacting text meaning is affected by editing processes because it is removed or causes the meaning to be changed. That is, it may be possible to keep semantic meaning in nonverbatim subtitles; however, coherence will certainly be removed. They also disagree with deleting conversational markers as an editing process. They claim: "conversational markers establish and maintain the relationships between participants in social interaction and thereby have a strong bearing on the atmosphere-more than the meaning-of the social interaction. Removing conversational markers seems to leave a very "dry' kind of conversation" (p.414).

\section{B. Previous Studies}

A number of studies have investigated the effect of various kinds of subtitling on various aspects of language and vocabulary learning:

Baltova (1999) assessed the effects of subtitling on foreign language vocabulary learning. He presented a seven-anda half minute video with various English and French audios and subtitles to 93 high school Canadian students studying French. He divided the participants into three groups: the first group was shown the video with English audio and French subtitles, the second group watched the video with French audio and subtitles, and finally the last group watched the video three times in French without any subtitles. After watching the video, ten short-answer, open-ended vocabulary questions were given to all the three groups. The analysis of the test results indicated that the second group watching the video with French audio and subtitles learned much more French vocabulary.

Koolstra and Beentjes (1999) compared the effect of three different versions of an English television program (original, subtitled in Dutch, and dubbed in Dutch) on Dutch children's vocabulary acquisition. The analyses revealed that Dutch children acquire more English vocabulary through Dutch subtitled version of English programs than through dubbed or original ones.

Kothari, Takeda, Joshi, and Pandey (2002) conducted a study to evaluate the effect of subtitles on foreign language learning. To this end, they used a film on three groups of 46 elementary school children learning English. The first group was provided with an English film subtitled in the native language. The second group was given the same film with no subtitles. But the last group was shown no films. Analysis of the results indicated that the first group was the best group in sustained recall and reading improvement. They also showed that the participants dealing with no subtitles achieved more improvements than the third group who did not watch the film at all.

Yuksel and Tanriverdi (2002) investigated the effects of intralingual subtitles on incidental vocabulary acquisition. They used 120 college intermediate students learning English as a foreign language at a Turkish university. About ten minutes of an episode of an American TV series was shown twice to the participants: one group watched the movie clip with English subtitles, whereas the other group watched it without any subtitles. The results of the study revealed that 
watching the movie clip had a significant effect on the participants' vocabulary knowledge. The caption group performed a little better than the control group.

Jones (2004) examined the effect of multimedia on language learners' vocabulary recognition and production. To do so, four English-speaking groups studying French participated in his study. At first, they were administered a vocabulary pretest to measure their prior knowledge of vocabulary. Then, the participants listened to a 2 minute and 20 second aural French passage several times. The first group had access to the images and simultaneous English written translations. The second group had access only to the images. The third one read simultaneous English written translations, and the last one was the control group and had access to nothing more than the pronunciation. After listening to the passage, they took two written and pictorial vocabulary recognition tests as well as a written vocabulary production test in order for the researcher to assess their improvements in vocabulary recognition and production. The results of the study indicated that the test mode did not play any significant role in vocabulary recognition. On the other hand, it had a positive effect on vocabulary production. In fact, the participants who had access to the images could not perform as well as those with English written translations. He concluded that the images improve vocabulary recognition, whereas written translations affect vocabulary production.

In order to assess the effect of subtitles in target language on vocabulary recognition, Stewart and Pertusa (2004) divided two Spanish films into segments. Then, they also divided seven intermediate Spanish conversation classes of English learners into two groups: showing each class one segment, 53 learners watched the segments of the Spanish films with Spanish subtitles, and 42 learners saw the same films subtitled in English. A multiple-choice test on a video film was administered to the participants before watching the films in order to measure their level of listening comprehension in Spanish. The results indicated that they were all at the same level. In addition, they were given a multiple-choice vocabulary pretest and post-test to measure the level of vocabulary learning. At the end of the study, they were also presented with a questionnaire to express their feelings about their experience. It turned out that there was a slight difference in the two groups' performance on the vocabulary post-test. However, the questionnaires showed that the learners who watched the segments with target language subtitles had better experiences with subtitling.

Analyzing the effect of nonverbatim subtitles on deaf or hearing-impaired viewers' film comprehension, Schilperoord, Groot, and Son (2005) broadcast three Dutch television programs with nonverbatim subtitles to a selection of Dutch deaf or hard of hearing participants. They chose two comic programs and one documentary. Then, they removed all marked coherence relations to formulate nonverbatim subtitles. The results of the study indicated that meaning was not preserved in nonverbatim captioning.

Bianchi and Ciabattoni (2008) investigated the short and long-term effects of captions and subtitles on the novice, intermediate, and advanced Italian learners of English. To accomplish this objective, 85 Italian college students of English participated voluntarily in the study. In the first phase, a multiple-choice pretest composed of four tasks was administered to the participants. Tasks 1 and 2 aimed at assessing the participants' level of grammar and general knowledge of vocabulary, respectively. The aims of tasks 3 and 4 were exactly the same as those of the first two tasks. However, the vocabulary and grammar points were chosen from among the film clips. The pretest helped the researchers assign the participants into three groups of novice, intermediate, and advanced levels. In the next phase, each level was divided into three groups. Each group watched several clips of the two English films with three versions as follows: captioned, subtitled in Italian, and original with no subtitles or captions. It is worth noting that here captioning and subtitling refer to intralingual and interlingual subtitling, respectively. They used individual computers with headphones. After the clips, a multiple-choice test was administered to assess the short-term effects of subtitling and captioning on comprehension of vocabulary and content and use of lexico-grammatical phrases. The participants could watch the clips again and review their answers. In the third phase, the participants were supposed to answer the same questions as administered in the pretest. It took place seven days after phase 2 in order to measure the long-term effects of subtitles and captions on vocabulary acquisition and content comprehension. Bianchi and Ciabattoni concluded that regardless of the proficiency level and type of film, subtitles led to the best result in content comprehension. Concerning vocabulary comprehension, subtitles were more useful than captioning, especially with regard to the learners of lower-proficiency level. Finally, although subtitles were generally a little more fruitful than captions in vocabulary acquisition, the novice learners took the greatest advantage from captions, compared with the intermediate and advanced learners.

Finally, Wang, et al. (2008) worked with two groups of Chinese students learning English on a bilingually subtitled animation movie for four weeks. At first, a pretest was given to the groups to identify the new words for all the participants. Both the experimental and comparison groups watched the movie with Chinese subtitles at the bottom of the screen in addition to English subtitles at the top. The only difference was that the experimental group had access to the new words beneath the Chinese subtitles. The results of the posttest indicated that the experimental group performed much better than the comparison group in English listening comprehension and vocabulary learning.

The above-mentioned studies reflect only part of the relevant literature. While a more thorough examination of the literature is not within the scope of this paper, such an examination will definitely highlight higher levels of controversy as to the effectiveness of various types of subtitling on vocabulary learning. In an attempt to resolve part of this controversy, the present study aims to investigate the effects of interlingual and intralingual verbatim and nonverbatim subtitling on vocabulary comprehension and production. 


\section{METHOD}

\section{A. Participants}

The participants were 120 intermediate-level English language learners studying conversational English. Some of the participants were studying at Jahad-e-daneshgahi and the rest were studying at Gouyesh institute in Qazvin. Fifty one of the participants were male and ninety three were female. Their age ranged from 19 to 32 .

\section{B. Instrumentation}

The movie she's the man was used as an experimental treatment in this study. The original movie lasts 3 hours; however, the summarized version lasting about 70 minutes was used in the present study. She's the man was directed by Andy Fickman in the United States in 2006. Because of the real-life and contextualized features, this movie was chosen to stimulate the viewers' interest. In addition, the genre of comedy and romance adds to its attractiveness.

A multiple-choice TOEFL test (the 1995 version) was administered to the participants as a criterion to assess their prior knowledge of the English language. It consisted of 100 questions including 40 grammatical items, 30 vocabulary items, and 30 reading comprehension items.

Prior to watching the movie, the participants received a vocabulary pretest consisting of 100 words which aimed at assessing their prior knowledge of the vocabulary used in the movie. The participants were supposed to write a synonym for the intended vocabulary items in Persian.

Additionally, two 3-item vocabulary posttests were also administered to the participants after watching the movie to measure vocabulary comprehension and production. The vocabulary comprehension items were in multiple-choice format and the vocabulary production test was administered in fill-in-the-blanks format in which the first letter of each intended word was given to the participants to avoid the possibility of the participants providing acceptable words which fitted the context without necessarily being the intended word.

\section{Procedure}

Initially, to homogenize the participants, a multiple-choice TOEFL proficiency test was administered to 144 participants. It consisted of 100 grammar, vocabulary and reading comprehension items. The analysis of the scores indicated that 21 of the participants had to be removed from the study due to a different proficiency level. Three other participants were also excluded from the study because they failed to complete their cooperation. There remained 120 participants.

Then, the vocabulary pretest was administered. The participants were required to write the Persian synonyms of 100 words that were extracted from the movie. The purpose of the pretest was to guarantee the lack of prior knowledge of the target words on the part of the participants and to identify the new or unfamiliar words for inclusion in the posttests.

The participants were then randomly divided into four groups of 30 . Each group watched the same film with a different type of subtitling: verbatim interlingual, nonverbatim interlingual, verbatim intralingual and nonverbatim intralingual subtitles. To make sure that they would watch the movie carefully, the participants were asked to write a one-page summary and hand in their summaries.

After delivering the summaries, the participants received the vocabulary comprehension and production posttests. In order to check the validity of the vocabulary comprehension and production posttests, it was piloted with a similar group of 30 students studying conversational English at the National Institute of English Language (NIEL) in Qazvin. To this end, the learners were given the TOEFL vocabulary subtest as well as the vocabulary comprehension and production posttests, and the correlation between the posttests and the TOEFL vocabulary subtest was measured using the Pearson correlation procedure. The correlation coefficients between the vocabulary comprehension test and the TOEFL vocabulary subtest and between the vocabulary production test and the TOEFL vocabulary subtest turned out to be .87 and .88 , respectively.

To investigate the effects of verbatim and nonverbatim interlingual and intralingual subtitles on vocabulary comprehension and production, two separate two-way ANOVA procedures were used.

\section{RESULTS AND DISCUSSION}

\section{A. Investigation of the First Research Question}

The first research question sought to investigate the effects of verbatim and nonverbatim interlingual and intralingual subtitling on $\mathrm{L}_{2}$ vocabulary comprehension. To answer this question, the results of the vocabulary comprehension test in the four groups were compared using a two-way ANOVA procedure. Descriptive statistics for the ANOVA on vocabulary comprehension are presented in table1. 
TABLE 1.

DESCRIPTIVE STATISTICS ON THE VOCABULARY COMPREHENSION TEST

\begin{tabular}{|c|c|c|c|c|}
\hline Language & Content & Mean & Std. Deviation & $\mathrm{N}$ \\
\hline \multirow{3}{*}{$\begin{array}{c}\text { Interlingual } \\
\text { subtitles }\end{array}$} & Verbatim subtitles & 9.13 & 5.36 & 30 \\
\cline { 2 - 5 } & Nonverbatim subtitles & 11.16 & 5.27 & 30 \\
\cline { 2 - 5 } & sum & 10.15 & 5.37 & 60 \\
\hline \multirow{2}{*}{$\begin{array}{c}\text { Intralingual } \\
\text { subtitles }\end{array}$} & Verbatim subtitles & 10.13 & 4.21 & 30 \\
\cline { 2 - 5 } & Nonverbatim subtitles & 12.56 & 3.56 & 30 \\
\cline { 2 - 5 } & sum & 11.35 & 4.06 & 60 \\
\hline
\end{tabular}

It can be seen from Table 1 that the mean scores the intralingual subtitles groups are higher than those of the participants of interlingual subtitles groups. In addition, in both the interlingual and intralingual subtitles groups, the participants of the group receiving nonverbatim subtitles have better performance than those receiving verbatim subtitles. To see whether or not the differences among the groups are statistically significant, the two-way ANOVA procedure was used, yielding the following results:

TABLE 2.

TWO-WAY ANOVA ON VOCABULARY COMPREHENSION

\begin{tabular}{|c|c|c|c|c|c|}
\hline Source & Type III Sum of Squares & df & Mean Square & F & Sig. \\
\hline Language & 43.200 & 1 & 43.20 & 1.98 & .16 \\
\hline Content & 149.633 & 1 & 149.63 & 6.87 & .01 \\
\hline Language* Content & 1.200 & 1 & 1.20 & .05 & .81 \\
\hline
\end{tabular}

According to the above table, the language of subtitles does not have a statistically significant effect on vocabulary comprehension. In other words, there is no significant difference between the effect of interlingual and intralingual subtitles on vocabulary comprehension (sig.=.16). However, the content of subtitles has a statistically significant effect on vocabulary comprehension. That is, nonverbatim subtitles significantly improve vocabulary comprehension (sig.=.01). Also, there is no statistically significant interaction effect between the language and the content of subtitles. We may conclude that nonverbatim subtitles result in more vocabulary comprehension regardless of whether they are interlingual or intralingual.

\section{B. Investigation of the Second Research Question}

The second question attempted to examine the effects of interlingual and intralingual verbatim and nonverbatim subtitling on $\mathrm{L}_{2}$ vocabulary production. Descriptive statistics needed for the ANOVA on vocabulary production are summarized in table 3 .

TABLE 3.

DESCRIPTIVE STATISTICS ON THE VOCABULARY PRODUCTION

\begin{tabular}{|c|c|c|c|c|}
\hline Language & Content & Mean & Std. Deviation & N \\
\hline \multirow{2}{*}{$\begin{array}{c}\text { Interlingual } \\
\text { subtitles }\end{array}$} & Verbatim subtitles & 1.76 & 1.25 & 30 \\
\cline { 2 - 4 } & Nonverbatim subtitles & 2.53 & 2.22 & 30 \\
\cline { 2 - 5 } & sum & 2.15 & 1.83 & 60 \\
\hline \multirow{2}{*}{$\begin{array}{c}\text { Intralingual } \\
\text { subtitles }\end{array}$} & Verbatim subtitles & 2.93 & 1.87 & 30 \\
\cline { 2 - 5 } & Nonverbatim subtitles & 3.43 & 2.48 & 30 \\
\cline { 2 - 5 } & sum & 3.18 & 2.19 & 60 \\
\hline
\end{tabular}

As it can be seen in the table, the participants of the intralingual subtitles groups achieved better results than the interlingual subtitles groups. In either of the interlingual and intralingual subtitles groups, the participants of the group receiving nonverbatim subtitles have outperformed those receiving verbatim subtitles. To see whether or not the observed differences among the groups are statistically significant, another two-way ANOVA procedure was used. The results of the ANOVA on vocabulary production are given in table 4.

TABLE 4.

TWO-WAY ANOVA ON VOCABULARY PRODUCTION

\begin{tabular}{|c|c|c|c|c|c|}
\hline Source & Type III Sum of Squares & df & Mean Square & F & Sig. \\
\hline Language & 32.033 & 1 & 32.033 & 7.905 & .006 \\
\hline Content & 12.033 & 1 & 12.033 & 2.970 & .088 \\
\hline Language * Content & .533 & 1 & .533 & .132 & .717 \\
\hline
\end{tabular}


According to table 4, the language of subtitles has a statistically significant effect on vocabulary production. In other words, intralingual subtitles contribute to vocabulary production significantly better than interlingual subtitles (sig.=.006). Moreover, although there is a relatively strong trend that the content of subtitles is an effective factor influencing vocabulary production, the difference between the verbatim and nonverbatim subtitle groups is not statistically significant (sig.=.08). In addition, there is no statistically significant interaction effect. This means that intralingual subtitles are more conducive to vocabulary production regardless of whether they are verbatim or nonverbatim.

The findings of the present study are in accordance with a number of previous studies (e.g. Baltova, 1999; Koolstra and Beentjes, 1999; and Jones, 2002), which support the effect of intralingual subtitles on vocabulary learning. However, the result of this study is different from a number of other studies (e.g. Bianchi \& Ciabattoni, 2008), which emphasize the more prominent role of interlingual subtitles in vocabulary learning. One of the possible reasons for such different results may be the different proficiency level of the participants in this study in comparison to the other studies. Another possible reason may be the fact that intralingual subtitles provide the opportunity for language learners to have access to the written forms of new words. Exposure to the written forms of words can be conducive to better performance on the vocabulary production test.

Furthermore, regarding the content of subtitles, the outcome of the present study is compatible with Cintas (2005) and Wang, et al. (2008), who seem to support the superiority of nonverbatim subtitles over verbatim subtitles. This could be partially attributed to the fact that nonverbatim subtitles are more easy-reading than verbatim subtitles. So, subtitling only lexical items draws the viewers' attention to the new words directly. Practically, because the participants in this research were intermediate level language learners, they were good enough in the other language skills and components. So, they did not need word for word statements or translations of the original dialogues.

Despite the apparent congruity of parts of the findings of this study with those of previous studies, the discrepancies between these finding and those of a group of other studies is possibly an endorsement of the need for further research.

\section{REFERENCES}

[1] Baltova, I. (1999). Multisensory language teaching in a multidimensional curriculum: The use of authentic bimodal video in core French. Canadian Modern Language Review, 56(1), 32-48.

[2] Bianchi, F. \& Ciabattoni, T. (2008). Captions and subtitles in EFL learning an investigative study in a comprehensive computer environment. Retrieved July 16, 2009, from http://www.opestarts.unit.it./dspace/bitstream/10077/2448/1/bianchi ciabattoni. pdf

[3] Bird, S. A. \& Williams, J. N (2002). The effect of bimodal input on implicit and explicit memory: an investigation into the benefits of within-language subtitling. Applied Psycholinguistics. University of Cambridge. Retrieved April 7, 2009, from http:// people.pwf.cam.ac.uk/jnw12/subtitling.pdf.

[4] Bravo, M. C. (2005). Foreign language learning made simpler by reading subtitles? Studies in teacher education; language, literature, and culture. Edited by Misztal, M. \& Trawinski, M. 105-114. Retrieved April 7, 2009, from http://members.chello.pl/ university/Language, \%20Literature\%20and\%20Culture.pdf

[5] Caimi, A. (2006). Audiovisual translation and language learning: the promotion of intralingual subtitles. The journal of specialized translation, 6, 85-97.

[6] Chang, J. Y. (2004). Captioned movies and vocabulary acquisition: Learning English through movies. M. A. proposal. University of Southern California.

[7] Cintas, J.D. (2005). Back to the future in subtitling. EU-High-Level Scientific Conference Series. MuTra 2005 - Challenges of Multidimensional Translation: Conference Proceedings. Retrieved April 7, 2009, from http://www.euro conferences.info/proceedings/2005_Proceedings/2005_DiazCintas_Jorge.pdf

[8] Cordella, M. (2007). Subtitling the film' The children of Russia': enhancing understanding through a series of linguistic transformations. Retrieved April 7, 2009, from http://www.institucional.us.es/revistas/ revistas/comunicacion/pdf/ numero

[9] Danan, M. (2004). Captioning and subtitling: undervalued language learning strategies. Erudite, 49(1), 67-77.

[10] Eken, A. N. (2003). You 've got a film': a film workshop. ELT journal, 57(1), 51-59.

[11] Gerzymisch-Arbogast. H. (2008). Introduction to multidimensional translation research. Retrieved April 21, 2009, from http://www.tanslationconcepts.org/pdf/ Multidimentional Translatin Research_Forli_05-2008.

[12] Jones, L. (2004). Testing $\mathrm{L}_{2}$ vocabulary recognition and recall using pictorial and written test items. Language learning and technology, 8(3), 122-143.

[13] Koolstra, C. M. \& Beentjes, J. W. J. (1999). Children vocabulary acquisition in a foreign language through watching subtitled television programs at home. ETR\&D, 47(1), 51-60.

[14] Kothari, B., Takeda, J., Joshi, A., \& Pandey, A. (2002). Same Language Subtitling: A Butterfly for Literacy? International Journal of Lifelong Education, 21(1), 55-56.

[15] Lever, H. J. (1998). MA in translation and interpreting. Chapter two-subtitling, 30-47. Retrieved May 25, 2009, from http://www.peak-translations.co.uk/ChapterTwo-Subtitling.doc

[16] Meskill, C. (1996). Listening skills development through multimedia. Jl. of Educational Multimedia and Hypermedia, 5(2), $179-201$.

[17] Neves, J. (2008). 10 fallacies about subtitling for the d/Deaf and the hard of hearing. The journal of specialized translation, 10.

[18] Reich, P. (2006). The film and the book in translation. MA thesis. Masaryk University. Retrieved April 21, 2009, from http://is.muni.cz/th/64544/ff_m/Diplomova_prace. doc

[19] Schilperoord, J. \& Groot, V. \& Son, N. (2005). Nonverbatim captioning in Dutch television programs: A text linguistic approach. Oxford journals. The journal of deaf studies and deaf education. 
[20] Schmidt, C. (2007). Same-language subtitling on television: a tool for promoting literacy retention in India. Retrieved April 21, 2009, from http://suseice. stanford.edu/ monographs/Schmidt_Clara.pdf.

[21] Schroter, T. (2005). Shun the pun, rescue the rhyme? - The dubbing and subtitling language- play in film. Karlstad university dissertation. Retrieved March 11, 2009, from http://www.kau.se/forskning/forskdb?to_do=show_result\&id=3275

[22] Stewart, M.A. \& Pertusa, I. (2004). Gains to language learners from viewing target language closed-captioned films. Foreign Language Annals, 37(3), 438-447.

[23] Wang, H., Chou, C., Wang, Y. \& Hsieh (2008), C. A preliminary study of the effect of listening comprehension, vocabulary and attitude on ESL learning in Taiwan. Retrieved March 11, 2009, from http://210.240.194.114/dct/studentsPaper/1108 08210041 eiL.pdf.

[24] Wang, Y. \& Shen, C. (2007). Tentative model of integrating authentic captioned video to facilitate ESL learning. Sino-Us English Teaching, 4(9), 1-13.

[25] Yuksel, D. \& Tanriverdi, B. (2002). Effects of watching captioned movie clip on vocabulary development of EFL learners. Retrieved March 23, 2009, from http://www.tojet.net /articles/824.doc.

[26] Zanon, N.T. (2006). Using subtitles to enhance foreign language learning. PORTA LINGUARUM 6. 41-52.

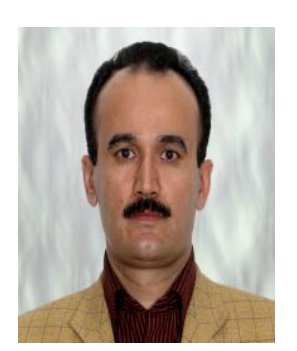

Abbas Ali Zarei is a Ph.D holder in Teaching English as a Foreign Language. He was born in Qazvin, Iran in 1972. In 1994, he got his BA in 'teaching English as a foreign language' from the University for Teacher Education in Tehran. He got his MA and PhD, both in 'TEFL' from Tehran University and Isfahan University in Iran in 1996 and 2002, respectively.

He is currently a member of academic staff at Imam Khomeini International University (IKIU) in Qazvin. $\mathrm{He}$ has 16 years of teaching experience. His main area of interest is vocabulary learning and the factors influencing it. He has written and published 14 books and translated four others. He has also had eleven articles published, mostly in the area of vocabulary learning.

Zohreh Rashvand is an MA holder in Teaching English as a Foreign Language. She was born in 1983 in Qazvin, Iran. In 2005, she got her BA in Translation of English Language. She got her MA in the course of Teaching English as a Foreign Language in 2009. She got her BA ad MA, both from Takestan Islamic Azad University in Iran.

She has worked in the field of English to Farsi translation, including translation and publication of "Go Team" by Ken Blanchard, in 2008. In the field of TEFL, she has participated in the conferences on issues in English Language Teaching in Iran, including IELTI-4 conference held in University of Tehran. 